\title{
The falling incidence of hematologic cancer after heart transplantation
}

\author{
M. G. Crespo-Leiro, J. Delgado-Jiménez, L. López, L. Alonso-Pulpón, F. González- \\ Vilchez, L. Almenar-Bonet, G. Rábago, F. Pérez-Villa, M. J. Paniagua Martín, J. M. \\ Arizón del Prado, I. Sousa-Casasnovas, N. Manito-Lorite, B. Díaz-Molina, D. Pascual- \\ Figal, E. Lage-Galle, T. Blasco-Peiró, L. De la Fuente-Galán and J. Muñiz
}

\begin{abstract}
Background. A number of changes in the management of heart transplantation (HT) patients have each tended to reduce the risk of post-HT hematologic cancer, but little information is available concerning the overall effect on incidence in the HT population.

Methods. Comparison of data from the Spanish Post-Heart-Transplantation Tumour Registry for the periods 19912000 and 2001-2010.

Results. The incidence among patients who underwent HT in the latter period was about half that observed in the former, with a particularly marked improvement in regard to incidence more than five yr post-HT.

Conclusions. Changes in HT patient management have jointly reduced the risk of hematologic cancer in the Spanish HT population. Long-term risk appears to have benefited more than short-term risk.
\end{abstract}

Key words: cancer incidence; heart transplantation; immunosuppressive therapy; long-term complications; lymphomas; mortality

Immunosuppression increases the risk of cancer. Among adult heart transplantation $(\mathrm{HT})$ patients, cancers cause about $15 \%$ of the deaths occurring between one and three yr post-HT, 22-24\% of those occurring between three and $15 \mathrm{yr}$ post-HT, and about $20 \%$ of those occurring thereafter; after five yr, they are the main cause of death [1]. In the absence of other causes of death, almost $50 \%$ of adult HT patients would develop some form of cancer within $15 \mathrm{yr}$ of transplantation [1].

Some $10-12 \%$ of all post-HT cancers are lymphomatous, with a two-yr post-diagnosis survival rate of only about $40 \%[1,2]$. Most are cases of post-transplant lymphoproliferative disease (PTLD), the immediate cause of which has long been known to be, in most cases, infection by Epstein-Barr virus (EBV) [3-5]. The risk of EBV-induced PTLD has been reported to be especially acute following the induction of immunosuppression by antibodies other than IL2R blockers, at least in the absence of effective antiviral prophylaxis [6-8].

Over the past decade, HT practice has been changing in regard to both immunosuppression and infection. Among the patients recorded in the ISHLT Registry, tacrolimus has to a large extent replaced cyclosporine, weaning from prednisone is increasingly common, and the use of azathioprine has practically disappeared, while use of mycophenolate mofetil is almost universal [1]. Induction with OKT3 is a thing of the past (this antibody is no longer marketed), while the use of IL2R blockers is increasing [1]. Antiviral prophylaxis and/or CMV viremia monitoring are now commonly considered when induction is performed with antithymocyte antibodies (ATG), at least when indicated by donor and recipient serology [9].

In Spain, around $90 \%$ of de novo HT patients now receive induction, about $80 \%$ with IL2R blockers [10]. Spanish centers have also been prominent in promoting antiviral prophylaxis as a means of preventing PTLD. Here, we report the results of a registry study undertaken to determine whether the incidence of PTLD and other hematologic cancers among Spanish HT patients exhibits the decreasing trend sought by these and other changes in practice. 


\section{Methods}

The Spanish Post-Heart-Transplantation Tumour Registry (SPHTTR) records follow-up data on all Spanish HT patients in regard to post-HT neoplasias. In this study, we initially included the records of all patients who underwent HT between 1991 and the end of 2010 aged 16 yr or more, and who survived at least three months after HT. Fifty-four patients were then excluded because of incomplete records. The remaining 4274-member study group $(83.2 \%$ male, age $52.1 \pm 11.0 \mathrm{yr})$ was divided in two subgroups on the basis of the date of HT: 1991-2000 (2299 patients) and 2001-2010 (1975 patients). Follow-up data were included up to the end of 2000 for the former subgroup (8804 person-yr), and up to the end of 2010 for the latter (9696 person-yr). One-yr, five-yr, and overall incidences of hematologic cancer were calculated for each of the two period groups, the corresponding between-period relative risks were determined, and Kaplan-Meier and cumulative incidence curves were constructed. The Kaplan-Meier curves of the two period groups were compared using the log rank test and the cumulative incidence curves using Gray's test [11].

The two period groups were compared, using chi-square or Fisher's exact tests, in regard to sex, distribution in age groups $(<45,45-54,55-64$, and $>64 \mathrm{yr})$, pre-HT smoking, pre-HT neoplasia, initial immunosuppression (cyclosporine, MMF, azathioprine, tacrolimus, everolimus, sirolimus), induction (OKT3, thymoglobulin, ATG, basiliximab, daclizumab, none), cytolytic induction (any of OKT3, ATG, and thymoglobulin vs. any of basiliximab, daclizumab, and none), antiviral prophylaxis with acyclovir or ganciclovir in the first three months, and CMV mismatch. Unless prevented by a zero incidence of lymphoma, between-period relative risks were calculated for the subgroups listed above using a Poisson model, and the desirability of adjusting the overall incidences and risk ratio was evaluated.

Statistical calculations were performed using Stata 10 or (for Gray's test) R. The institutional review board of each participating center approved this research protocol.

\section{Results}

In all, 44 patients developed hematologic cancer, 30 before and 14 in or after 2001. No patient developed a second hematologic cancer during his or her follow-up period in this study, and none of these 44 patients had suffered a pre-HT neoplasia. Forty cancers were lymphomas and four leukemias.

The one-yr, five-yr, and overall incidence rates were all lower in the second period than the first (Table 1), although only the fall in the overall incidence rate from 3.41 to 1.44 per 1000 person-yr (relative risk 0.42$)$ was statistically significant $(\mathrm{p}=0.009)$. In keeping with these trends, the cumulative incidence curves (plots of cumulative incidence of hematologic cancer within $x$ years of HT, vs. $x$ ) differed significantly $(\mathrm{p}=0.014)$, the curve for 2001-2010 lying below the curve for 1991-2000 (Fig. 1). The Kaplan-Meier curves (not shown), which also differ significantly ( $\mathrm{p}=0.007$ ), are very similar to the cumulative incidence curves and lie only slightly above them, especially in the case of the period 20012010, for which the Kaplan-Meier and cumulative incidence curves practically coincide.

Table 1. One- and five-yr incidence of hematologic cancer among Spanish patients undergoing HT in each period, per 1000 personyr, together with the whole-group incidences

\begin{tabular}{|c|c|c|c|c|c|c|c|}
\hline \multicolumn{8}{|l|}{ One-yr } \\
\hline 1991-2000 & 2085.2 & 10 & 4.80 & $2.58-8.91$ & 1.00 & - & - \\
\hline 2001-2010 & 1875.6 & 4 & 2.13 & $0.8-5.68$ & 0.45 & $0.10-1.54$ & 0.253 \\
\hline \multicolumn{8}{|l|}{ Five-yr } \\
\hline $2001-2010$ & 7336.8 & 12 & 1.64 & $0.93-2.88$ & 0.55 & $0.25-1.17$ & 0.134 \\
\hline \multicolumn{8}{|l|}{ By period } \\
\hline $1991-2000$ & 8804.1 & 30 & 3.41 & $2.38-4.87$ & 1.00 & - & - \\
\hline 2001-2010 & 9696.3 & 14 & 1.44 & $0.86-2.44$ & 0.42 & $0.21-0.82$ & 0.009 \\
\hline
\end{tabular}




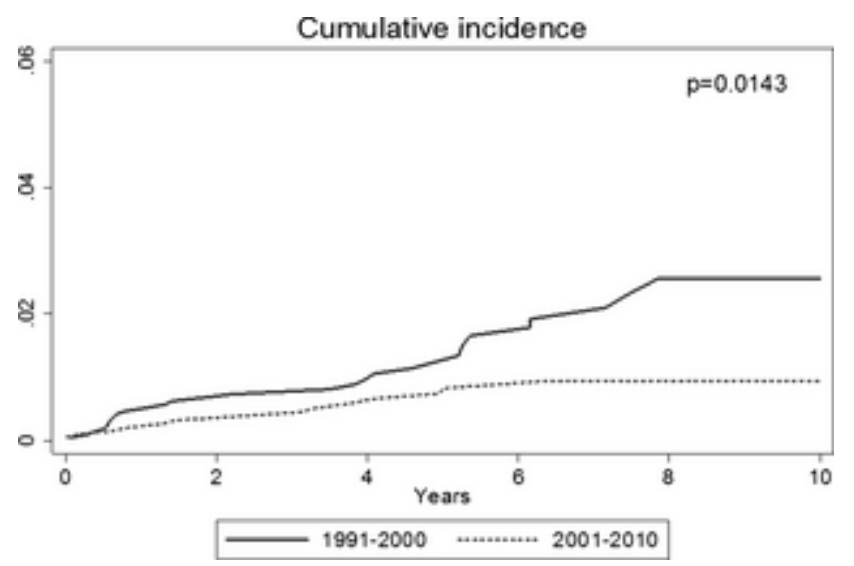

Figure 1. Cumulative incidence of hematologic cancer among Spanish patients undergoing HT in the periods 1991-2000 and 2001$2010(\mathrm{p}=0.0143)$.

The pre-2001 and post-2000 patient groups differed significantly $(\mathrm{p}<0.001)$ in regard to all the variables considered except pre-HT smoking $(\mathrm{p}=0.139)$ (Table 2). In regard to patient characteristics, the main differences were an increase in the proportion of female patients; a similar increase in the proportion of patients aged $\geq 65$ years, largely at the expense of the 45-64-yr-old group; and an increase in transplants with CMV-positive donors and CMV-negative receptors. In regard to treatment variables, Table 2 shows the same trends in immunosuppression and induction as were noted above in the Introduction (although cyclosporine continued to be used almost twice as often as tacrolimus for initial immunosuppression), and there was also an increase in the prophylactic use of antivirals in the first three months post-HT. Notably, the prevalence of cytolytic induction fell from $69 \%$ to $11 \%$ with the introduction of IL-2 blockers (which also brought a fall in the number of patients given no induction therapy). 
Table 2. Characteristics of Spanish HT patients, 1991-2000, and 2001-2010

\begin{tabular}{|c|c|c|c|}
\hline & $\begin{array}{c}1991-2000 \\
\text { n }(\%)\end{array}$ & $\begin{array}{c}2001-2010 \\
\text { n (\%) }\end{array}$ & $\mathrm{p}$ \\
\hline Sex & 2299 & 1975 & \\
\hline Men & $1958(85.2)$ & $1596(80.8)$ & $<0.001$ \\
\hline Women & $341(14.8)$ & $379(19.2)$ & \\
\hline Age group (yr) & 2299 & 1975 & \\
\hline$<45$ & $480(20.9)$ & 407 (20.6) & $<0.001$ \\
\hline $45-54$ & $706(30.7)$ & $553(28.0)$ & \\
\hline $55-64$ & $977(42.5)$ & $811(41.1)$ & \\
\hline$\geq 65$ & $136(5.9)$ & $204(10.3)$ & \\
\hline Pre-HT smoker & 1874 & 1726 & \\
\hline No & $732(39.1)$ & $716(41.5)$ & 0.139 \\
\hline Yes & $1142(60.9)$ & $1010(58.5)$ & \\
\hline Pre-HT cancer & 2299 & 1975 & \\
\hline No & $2264(98.5)$ & $1919(97.2)$ & 0.002 \\
\hline Yes & $35(1.5)$ & $56(2.8)$ & \\
\hline $\mathrm{CMV}+/-$ (donor/receptor) & 2040 & 1750 & \\
\hline No & $1905(93.4)$ & $1554(88.8)$ & $<0.001$ \\
\hline Yes & $135(6.6)$ & $196(11.2)$ & \\
\hline Initial immunosuppression & 2299 & 1975 & \\
\hline Cyclosporine & $2142(93.2)$ & $1142(57.8)$ & $<0.001$ \\
\hline Mycophenolate mofetil & $371(16.1)$ & $1557(78.8)$ & $<0.001$ \\
\hline Azathioprine & $1850(80.5)$ & $199(10.1)$ & $<0.001$ \\
\hline Tacrolimus & $92(4.0)$ & $653(33.1)$ & $<0.001$ \\
\hline Everolimus & $6(0.3)$ & $62(3.1)$ & $<0.001$ \\
\hline Sirolimus & $8(0.3)$ & $38(1.9)$ & $<0.001$ \\
\hline Induction & 2299 & 1975 & \\
\hline OKT3 & $1210(52.6)$ & $176(8.9)$ & $<0.001$ \\
\hline Daclizumab & $1(0.0)$ & $451(22.8)$ & $<0.001$ \\
\hline None & $702(30.5)$ & $489(24.8)$ & $<0.001$ \\
\hline Cytolytic inductiona & 2299 & 1975 & \\
\hline No & $709(30.8)$ & 1755 (88.9) & $<0.001$ \\
\hline Yes & $1590(69.2)$ & $220(11.1)$ & \\
\hline Antiviral prophylaxisb & 2299 & 1908 & \\
\hline No & $1086(47.2)$ & $726(38.1)$ & $<0.001$ \\
\hline Yes & $1213(52.8)$ & $1182(61.9)$ & \\
\hline
\end{tabular}

${ }^{a}$ OKT3, thymoglobulin or antithymocyte globulin.

${ }^{b}$ Acyclovir or ganciclovir in the first three months post-HT.

\section{Discussion}

The above results show that the incidence of post-HT hematologic cancer was significantly lower in the period 2001-2010 than in the preceding decade. This conclusion is supported by analysis of the raw incidence data and of cumulative incidence and Kaplan-Meier curves. Although the present study is too small to allow more detailed firm inferences concerning a complication that only affects around 5\% of HT patients, the particularly striking divergence between the two cumulative incidence curves for the period more than about five yr post-HT suggests that changes in HT practice may have reduced the risk of late development of hematologic cancer rather than that of early development.

Although this study was conceived largely as a comparison of the pre- and post-IL2R-blocker eras, and the SPHTTR records go back to 1984, the two periods compared were both $10 \mathrm{yr}$ long. This was in order to minimize between-group differences in the influence of post-HT time on risk. Even so, the two groups of patients differed in this respect, because in general the number of heart transplantations per year increased during the 1990s and has since then shown a decreasing trend [10]. Note, however, that these trends reinforce the conclusion that the risk of hematologic cancer has decreased, as they imply that the average follow-up time was longer in the 2001-2010 group than in the 1991-2000 group.

The similarity of the cumulative incidence curves to the corresponding Kaplan-Meier curves, which estimate the trends in intrinsic risk of hematologic cancer (i.e., the risk there would be in the absence of other causes of death), suggests that realization of a reduction in intrinsic risk has not been prevented to any great extent by death from other causes. The fact that the Kaplan-Meier and cumulative incidence curves for 2001-2010 are closer to each other than those for 1991-2000 is consistent with changes in practice having delayed death from other causes as well as reducing the risk of hematologic cancer. 
It was not considered appropriate to correct the raw incidence rates and relative risks of Table 1 for the effects of any of the variables included in Table 2. Adjustment was generally ruled out by zero incidence in one or both periods in one or more of the relevant subgroups; by there being large numbers of missing data (pre-HT smoking, CMV status); or by one or more of the strata having very few members (e.g., very few patients received sirolimus). Fig. 2 shows the ratio of risk in 2001-2010 to risk in 19912000 for all strata for which this was not the case. Most of the variables in Fig. 2 are not suitable for correction of the raw incidences because they may be causally involved in the change in raw incidence between the earlier period and the later: this is the case of induction, cytolytic induction, OKT3, azathioprine, and antiviral prophylaxis (additionally, for cytolytic induction, OKT3 and azathioprine there are rather few members in one of the strata in one of the periods). The remaining variables, sex and age group, showed no significant relative risk differences between strata, and correction for these variables had little or no effect on overall relative risk, which was still 0.42 when corrected for age group and 0.44 when corrected for sex.

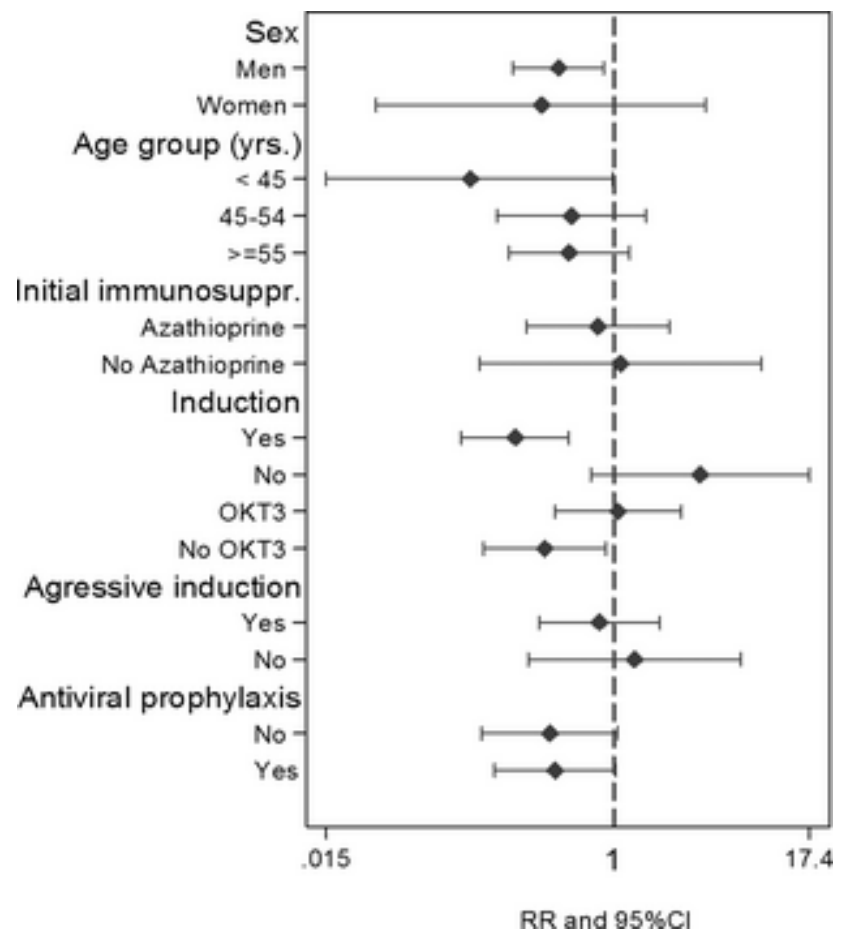

Figure 2. Relative risk of hematologic cancer among various subgroups of Spanish HT patients (2001-2010 vs. 1991-2000). Bars indicate $95 \%$ confidence intervals. Only three age groups are considered, because of zero incidence among patients aged $>64$ yr in the period 2001-2010.

Although the above reasons rule out the use of the data of Fig. 2 to correct raw incidences, these data are not without interest. They show that most of the groups for which it was possible to calculate relative risk showed some reduction in risk, although the reduction did not always attain statistical significance. This supports the notion that the causes of the reduction in risk between the first period and the second were multifactorial.

The main exception to the trend just noted is the group of patients who received no induction treatment: incidence among the 489 who received no induction in 2001-2010 was higher than among the 702 who received no induction in 1991-2000. However, in the absence of a plausible medical explanation of this difference, it seems likely that this increase in observed incidence may actually have been due to chance.

A limitation of the study is that for a number of variables that in principle might be expected to be relevant to the incidence of hematologic cancer, it was not possible to compare the two period groups because they are not recorded in the SPHTTR. They include donor-receptor EBV mismatch and pre-HT risk factors for malignancy other than smoking and malignancy itself. 
In conclusion, in the decade 2001-2010 the incidence of hematologic cancer among patients who underwent HT in this period was about half that observed in the period 1991-2000. The reduction appears to be particularly marked in regard to long-term incidence.

\title{
Acknowledgements
}

We are grateful to the researchers and staff of all the Spanish heart transplant centers that contributed data to this study, to Zulaika Grille and ODDS for helping with study coordination, to Soly Santiago for the statistical analyses, tables and figures, and to Ian-Charles Coleman for helpful suggestions and for the English version of this paper. The Spanish Post-Heart-Transplant Tumour Registry is partially supported by an unrestricted grant from Novartis. This study formed part of the clinical and translational heart failure research program of the cardiovascular disease network of the Instituto de Salud Carlos III (RD12/0042), of which several of the present authors are members.

\section{Authors' contributions}

María G. Crespo-Leiro: Participated in study design, plan of data analysis, recruitment of participants, writing of the first draft of the manuscript and critical revision of the article, and approval of its final version; Juan Delgado-Jiménez, Laura López, Luis Alonso-Pulpón, Francisco González-Vilchez Luis Almenar-Bonet, Gregorio Rábago, Félix Pérez-Villa, María J. Paniagua-Martín, José M. Arizón del Prado, Iago Sousa-Casasnovas, Nicolás Manito-Lorite, Beatriz Díaz-Molina, Domingo Pascual-Figal, Ernesto Lage-Galle, Teresa Blasco-Peiró, and Luis de la Fuente-Galán: Participated in study design, recruitment of participants, critical revision of the article, and approval of its final version; and Javier Muñiz: Participated in data analysis, writing of the first draft of the manuscript and critical revision of the article, and approval of its final version.

\begin{abstract}
Appendix
Other investigators involved in maintaining the Spanish Post-Heart Transplant Tumour Registry are as follows: Marta Paradinas, María Vicente, Nuria Ochoa, Miguel Angel Gómez, Pilar Escribano and María José Ruiz Cano (Hospital Universitario 12 de Octubre, Madrid); Eulàlia Roig, Sonia Mirabet and Vicens Brossa (Hospital Santa Creu i Sant Pau, Barcelona); Javier Segovia Cubero and Manuel Gómez Bueno (Hospital Universitario Puerta de Hierro, Madrid); José Antonio Vázquez de Prada (Hospital Universitario Marqués de Valdecilla, Santander); Luis Martínez, Ignacio Sánchez-Lázaro and Mónica Cebrián (Hospital Universitari i Politècnic La Fe, Valencia); Montserrat Lorente (Clínica Universidad de Navarra, Pamplona); Montserrat Cardona, $\mathbf{M}^{\mathrm{a}}$ Angeles Castel and Marta Farrero (Hospital Clínic i Provincial, Barcelona); Raquel Marzoa-Rivas, Eduardo Barge-Caballero, Carmen Naya Leira, Pilar Fariñas Garrido and Paula Blanco Canosa (Hospital Universitario A Coruña, La Coruña); Amador LópezGranados (Hospital Universitario Reina Sofía, Córdoba); Adolfo Villa Arranz, Jesús Palomo and Juan Fernández-Yáñez (Hospital General Universitario Gregorio Marañón, Madrid); José González-Costello and Josep Roca (Hospital Universitari de Bellvitge, Barcelona); José Luis Lambert Rodríguez and María José Bernardo Rodríguez (Hospital Universitario Central de Asturias, Oviedo); Iris Garrido Bravo (Hospital Universitario Virgen de la Arrixaca, Murcia); J. Manuel Sobrino (Hospital Universitario Virgen del Rocío, Sevilla); Marisa Sanz Julve (Hospital Universitario Miguel Servet, Zaragoza); Javier López Díaz (Hospital Clínico Universitario de Valladolid, Valladolid).
\end{abstract}

\section{References}

1. Stehlik J, Edwards LB, Kucheryavaya AY et al. The Registry of the International Society for Heart and Lung Transplantation: Twenty-eighth Adult Heart Transplant Report - 2011. J Heart Lung Transplant 2011: 30: 1078.

2. Crespo-Leiro MG, Alonso-Pulpón L, Vázquez de Prada JA et al. Malignancy after heart transplantation: incidence, prognosis and risk factors. Am J Transplant 2008: 8: 1031.

3. Purtilo DT. Epstein-Barr-virus-induced oncogenesis in immune-deficient individuals. Lancet 1980: 1: 300.

4. Saemundsen AK, Purtilo DT, Sakamoto K et al. Documentation of Epstein-Barr virus infection in immunodeficient patients with life-threatening lymphoproliferative diseases by Epstein-Barr virus complementary RNA/DNA and viral DNA/DNA hybridization. Cancer Res 1981: 41: 4237.

5. Hanto DW, Gajl-Peczalska KJ, Frizzera G et al. Epstein-Barr virus (EBV) induced polyclonal and monoclonal Bcell lymphoproliferative diseases occurring after renal transplantation. Ann Surg 1983: 198: 356.

6. Opelz G, Dohler B. Lymphomas after solid organ transplantation: a collaborative transplant study report. Am J Transplant 2003: 4: 222. 
7. Crespo-Leiro MG, Alonso-Pulpón L, Arizón JM et al. Influence of induction therapy, immunosuppressive regimen and antiviral prophylaxis on development of lymphomas after heart transplantation: data from the Spanish PostHeart-Transplant Tumour Registry. J Heart Lung Transplant 2007: 26: 1105.

8. Issa NC, Fishman JA. Infectious complications of antilymphocyte therapies in solid organ transplantation. Clin Infect Dis 2009: 48: 772.

9. Haddad H, Isaac D, Legare JF et al. Canadian Cardiovascular Society Consensus Conference update on cardiac transplantation 2008: executive Summary. Can J Cardiol 2009: 25: 197.

10. Almenar L, Segovia J, Crespo-Leiro MG et al. Spanish registry on heart transplantation. 23rd official report of the Spanish Society of Cardiology Working Group on Heart Failure and Heart Transplantation (1984-2011). Rev Esp Cardiol (Engl Ed) 2012: 65: 1030.

11. Gray RJ. A class of K-sample tests for comparing the cumulative incidence of a competing risk. Ann Stat 1988: 16: 1141 